\title{
ANALYSIS OF ISSUES AND CONSTRAINTS ASSOCIATED WITH PLASTIC RECYCLING INDUSTRY IN SRI LANKA
}

\author{
G.P.N. Gunarathna ${ }^{1 *}$, N.J.G.J. Bandara ${ }^{1}$ and S.Liyanage ${ }^{2}$ \\ ${ }^{1}$ Department of Forestry and Environmental Science, University of Sri Jayewardenepura, Sri Lanka \\ ${ }^{2}$ Department of Chemistry, University of Sri Jayewardenepura, Sri Lanka \\ *E mail n.padmi55@yahoo.com
}

\begin{abstract}
High consumption of plastics inevitably leads to the production of large amounts of plastic waste especially because a substantial part of produced plastics is used for packaging. Therefore, suppression of environmental pollution by plastic waste is a task of significant importance. Main objectives of the study are to assess the current status of plastic recycling industry in Sri Lanka and identification of issues related to plastic recycling industry. A questionnaire survey was carried out to collect data from all plastic waste collectors and recyclers registered in the CEA. Field observations were taken by studying twenty randomly selected plastic recycling industries in the Western Province.
\end{abstract}

The highest percentage (93\%) of recyclers use PP (Polypropylene) as a raw material in plastic recycling industry in Sri Lanka compared to other polymers. Waste collection by waste pickers from dumps and streets are the main source of plastic waste collection for recycling. About $95 \%$ of plastic and polythene waste obtained for recycling are in unsorted condition and $91 \%$ are in unclean condition. Private wells are the most widely used $(72 \%)$ source of water for washing of waste plastic. None of the plastic and polythene waste recycling industries in Sri Lanka has a wastewater treatment facility. Therefore $78 \%$ of plastic and polythene waste collectors and recyclers discharge their industrial wastewater in to the nearest water body.

Field observations indicate that most of the plastic waste recycling industries are running under capacity due to insufficient collection of plastic materials. In addition, lack of standard techniques for waste plastic sorting, problems of getting EPL and not having suitable lands for the establishment of large scale waste plastic recycling plants are the major issues currently faced by the plastic waste recycling industries in the Western Province.

\section{INTRODUCTION}

Discarded polythene and plastics, because of widespread use, are one of the biggest problems encountered in waste management. Another reason is that they are not bio degradable, and remain in the environment once disposed of. Due to their unique properties, plastics can hardly be substituted by other materials and, therefore, their collection and recycling is the only way to avoid environmental pollution (Fortelny et al., 2004). The growth of plastic waste has a great impact on the management of MSW by land filling and incineration, because available capacity for landfill of MSW is declining and plastics incineration may cause emissions of toxic fly and bottom ash which contain lead and cadmium (Shent et al., 1998). Plastic waste recycling is a method of reducing the quantity of net discards of MSW. Although the benefits have not been quantified, plastics recycling also offers the potential to generate demonstrable savings in fossil fuel consumption, both because the recycled plastic can supplement and even compete with 'virgin' resins produced from refined fossil fuel and because the energy required to yield recycled plastics may be less than that consumed in the production of the same resins from virgin feedstocks (Shent et al., 1998). 
Therefore, plastic waste recycling conserves both material and energy and provides a comparatively simple way to make a substantial reduction in the overall volume of MSW.

Sri Lanka imports 160,000 metric tons of plastic raw materials and another 100,000 metric tons of finished and intermediate products every year. Most of them remain in the environment as post consumer plastic and polythene waste causing severe environmental and health problems. Hence waste plastic collection and recycling has been an important strategy in order to reduce the amount of plastic and polythene waste accumulated in the environment. This study analyses the current status of plastic recycling industry in Sri Lanka and the issues and constraints related to the plastic recycling practices such as environmental issues, technical issues in the process and market issues.

\section{MATERIALS AND METHODS}

\subsection{SURVEY OF PLASTIC WASTE COLLECTORS AND RECYCLERS}

A questionnaire was given to all polythene and plastic waste collectors and recyclers registered in the Central Environmental Authority in Sri Lanka in order to gather information on current plastic waste collection, sorting, washing and recycling techniques and composition. Total sample size was 95 plastic waste collectors and recyclers. In this questionnaire, there were twenty main questions. This was designed to assess the current status of plastic waste recycling in Sri Lanka.

\subsection{FIELD SURVEY OF PLASTIC RECYCLING INDUSTRIES}

Western Province was selected as the study area for the field survey since most of the plastic waste recycling industries are concentrated in the Western Province. The polythene and plastic waste recycling process, relevant waste generation points, types of waste generated, technical and logistical barriers to recycling of plastic wastes and practical issues related to plastic recycling industry were studied. Twenty plastic waste recycling industries were randomly selected for the study.

\subsection{DATA ANALYSIS}

The collected data were analyzed qualitatively and quantitatively. Statistical analyses were carried out in order to obtain more precise findings from this study.

\section{RESULTS}

\subsection{RESULTS OF SURVEY I (PLASTIC WASTE RECYCLERS)}

\subsubsection{POLYTHENE AND PLASTIC WASTE COMPOSITION}

Plastic and polythene waste used in recycling industry mainly consist of Polypropylene (PP), Poly ethylene terephthalate (PET), High density poly ethylene (HDPE), Low density poly ethylene (LDPE), Polystyrene (PS), Poly vinyl chloride (PVC), Acyrlonitrile butadiene styrene (ABS), Poly carbonate (PC) and other polymer materials. PP has the highest percentage (93\%) of the composition of plastic waste and HDPE has the second highest value $(86 \%)$ followed by LDPE (84\%), PET (73\%), PS (55\%), PC (34\%), ABS (30\%), PVC (24\%) and other (13\%).

\subsubsection{METHODS OF COLLECTING POLYTHENE AND PLASTIC WASTE FOR RECYCLING}

According to the survey results, most of the polythene and plastic waste recyclers (98\%) collect raw waste plastic and polythene material through waste pickers from dumps and streets. Factory rejects from industries are the second highest (64\%) plastic waste source for polythene and plastic waste collectors an recyclers followed by collection centers (43\%), Urban Councils (20\%) and other (16\%). 


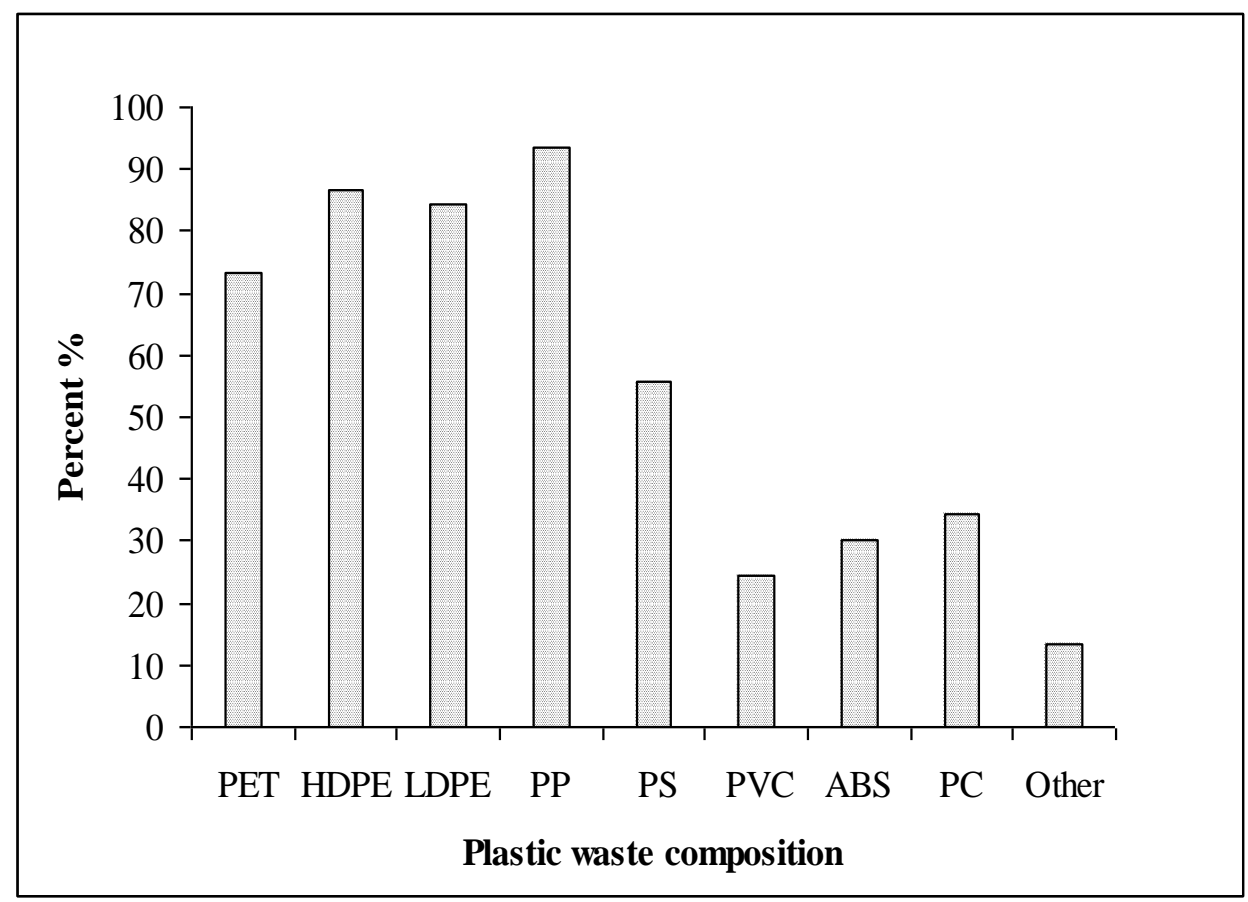

Figure 3.1: Polythene and plastic waste composition used for recycling industry in Sri Lanka

\subsubsection{FORM OF POLYTHENE AND PLASTIC WASTE AND THEIR PROCESSING}

The highest percentage $(95 \%)$ of waste polythene and plastic obtained are in unsorted condition. The second highest percentage $(91 \%)$ of waste plastic and polythene obtained for recycling are in unclean condition followed by clean $(23 \%)$ and sorted $(20 \%)$ waste polythene and plastic. Polythene and plastic waste processing consists of five major steps as sorting of plastic waste, washing, crushing, palletizing and manufacturing of new products. All the polythene and plastic waste collectors and recyclers surveyed don't go through the entire process. Out of collectors and recyclers, $67 \%$ of collectors and recyclers practice sorting of plastic waste while $63 \%$ practice washing. When $42 \%$ of polythene and plastic waste collectors and recyclers carry out crushing, only $35 \%$ of recyclers out of them go up to palletizing. Others sell crushed plastic to the market without further processing. However, the percentage of polythene and plastic waste collectors and recyclers who go through the entire process is $27 \%$ only.

\subsubsection{POLYTHENE AND PLASTIC WASTE IDENTIFICATION AND SORTING}

For sorting of plastic and polythene was done through various identification techniques. Colour is used by highest percentage (93\%) of recyclers in order to identify waste plastic and polythene and sound of waste plastic material is used by the second highest percentage $(81 \%)$ of recyclers followed by plastic code number (77\%), type of moulding (51\%) and other (42\%). According to the survey results, $100 \%$ of plastic and polythene waste collectors and recyclers practiced manual sorting in order to sort out waste plastic and polythene for recycling. Therefore none of the plastic and polythene waste collectors or recyclers practiced mechanical sorting in plastic waste recycling industry in Sri Lanka.

\subsubsection{POLYTHENE AND PLASTIC WASTE WASHING AND USE OF WATER SOURCES}

Out of ninety plastic and polythene waste collectors and recyclers surveyed, the highest percentage (99\%) of plastic and polythene waste recyclers use manual washing as washing technique. Mechanical washing is done by $1 \%$ of recyclers. Private well is the highest used (72\%) water source 
for washing of polythene and plastic waste in recycling industry in Sri Lanka. River water is the second highest used (14\%) water source followed by tap water (11\%) and other sources (3\%).

\subsubsection{WASTEWATER DISCHARGE POINTS}

According to the survey results, none of the plastic and polythene waste recycling industries in Sri Lanka has a wastewater treatment facility. The highest percentage (78\%) of plastic and polythene waste collectors and recyclers discharge their industrial wastewater into the nearest water body. Discharge to the road storm water drainage system is the second highest $(10 \%)$ wastewater discharge practice followed by to an unsealed tank in the ground (8\%) and other (4\%).

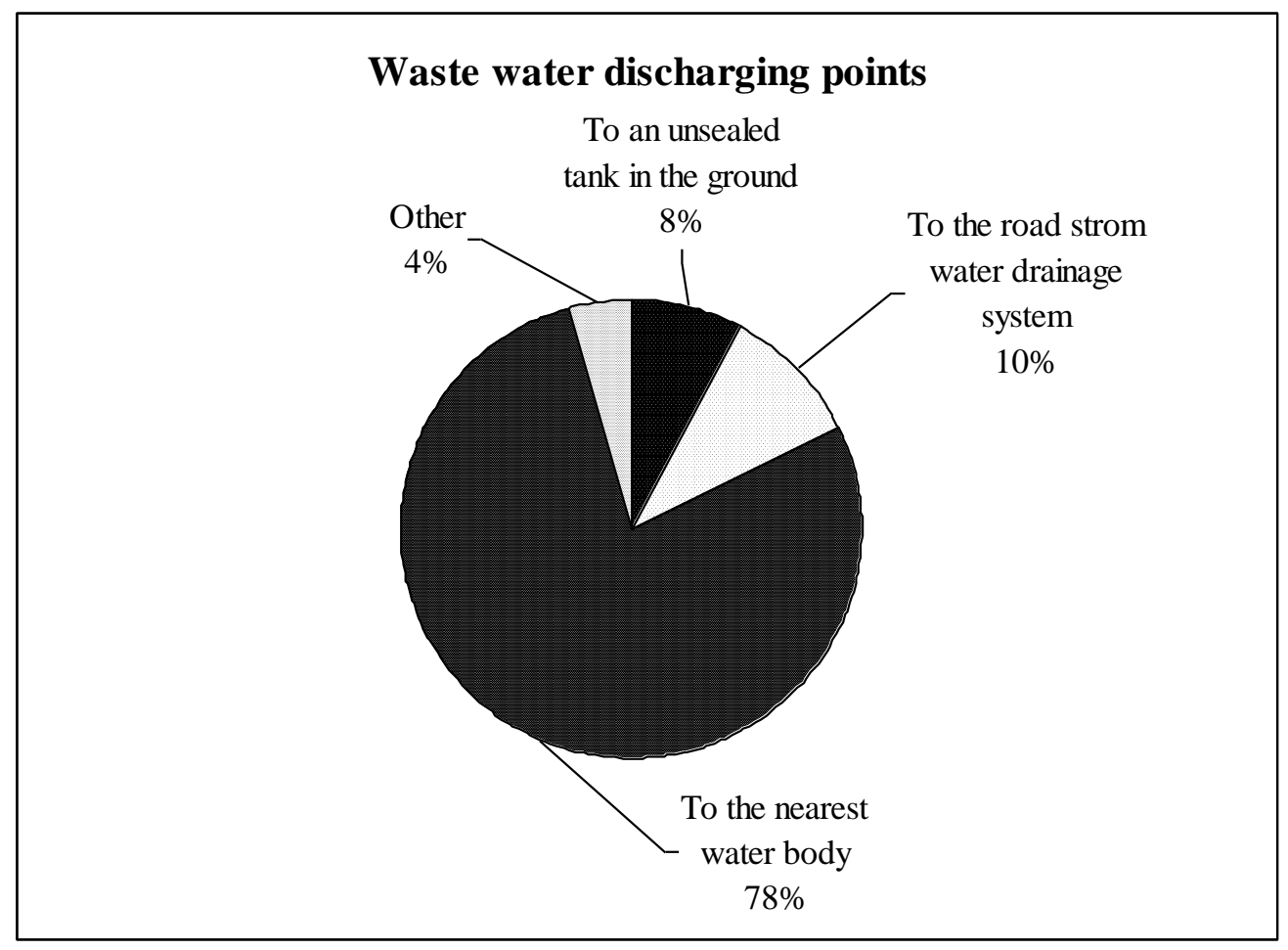

Figure 3.2: The percentage of waste water discharge in to different points

\subsubsection{WILLINGNESS TO INSTALL A WASTEWATER TREATMENT PLANT}

According to the survey results, about $88 \%$ of plastic and polythene waste recyclers are willing to install a wastewater treatment plant for their industries. However, about $12 \%$ of plastic and polythene waste recyclers are reluctant to install a wastewater treatment plant in their industries due to high cost of installation and maintenance.

\subsection{IDENTIFICATION OF ISSUES IN PLASTIC RECYCLING INDUSTRIES IN THE WESTERN PROVINCE THROUGH FIELD OBSERVATION}

Out of twenty plastic waste recycling industries surveyed in Western Province, Seventeen industries are having a problem of identification and sorting of waste plastic due to lack of standard techniques for waste plastic sorting. All the recycling industries surveyed don't have a proper way to discharge wastewater generated during washing of waste plastic. Therefore, all of these plastic waste recycling industries don't have an Environmental Protection Licence. 
In addition to that, all the plastic waste recycling industries surveyed during the study are having a low market price for their recycled products when virgin plastic are available at low prices. Lack of raw materials (collected waste plastic and polythene) for recycling is also a major issue which is faced by all the plastic waste recyclers surveyed. Since working with waste material is considered as an odd job by people in the society, there is a difficulty of finding workers for all plastic waste recycling industries. Out of twenty recycling industries surveyed, five industries have a problem of not having a suitable land to establish large scale plastic waste recycling plants. All the waste plastic recyclers have a problem of mosquitoes due to storage of collected waste plastic before processing. According to the plastic waste recyclers, government support for plastic waste recycling industry is not adequate.

\section{DISCUSSION}

When the data were collected, attention was given to polythene and plastic waste composition, methods of polythene and plastic waste collection, form of collected waste plastic, processing techniques, etc. The study had to be restricted to only plastic and polythene waste recyclers and collectors registered in the Central Environmental Authority as it is the only reliable source of polythene and plastic waste collectors and recyclers available in Sri Lanka.

Since factory rejects are in clean condition, the cost of washing is low when compared to other plastic wastes. Therefore, recyclers prefer to obtain factory rejects. However, some industries give their factory rejects to municipal solid waste collectors for disposal. Factory rejects are contaminated when mixed with garbage. Hence, industries should be made aware to provide their factory rejects directly to recycling industries in order to reduce the amount of plastic and polythene waste accumulated in the environment.

Since the highest percentage of plastic and polythene waste obtained for recycling is in unclean (91\%) and unsorted (95\%) condition, the cost of sorting and washing is high in plastic waste recycling industries in Sri Lanka. Processing of waste plastic and polythene mainly consist of five major steps such as sorting, washing, crushing, palletizing and manufacturing. The percentage of recyclers who carry out manufacturing is low (27\%) since some of the recyclers sell crushed plastics and pellets to the market rather than produce new goods.

Most of the polythene and plastic waste collectors and recyclers (93\%) identify and sort plastic waste using color as a sorting technique. However, color may not be a good sorting technique as different types of plastic products can have the same color. When different types of plastics are mixed together during processing, the final product can show defects. Moreover, mixed plastics can not be processed to produce new products. Sorting and washing activities are carried out by the laborers manually with their experience and ability.

According to the survey results, private wells are the main source of water $(72 \%)$ used by polythene and plastic waste collectors and recyclers for washing purposes. The reason may be that well water is freely and readily available compared with other water sources. None of the plastic recycling industries in Sri Lanka has a wastewater treatment facility for effluent discharged by washing of plastic waste. Hence, most of the recycling industries (78\%) discharge their wastewater in to the nearest water bodies without any treatment. This wastewater may contain feacal coliform since waste plastic which is collected from dump sites can be contaminated with feacal matter. Oil and grease may be detected from washing effluent due to the source of polythene and plastic waste collected such as lubricant oil cans, vegetable and cooking oil PET bottles. Heavy metals also can be present in the washing effluent as washing of battery containers can cause heavy metal release to washing effluent. Furthermore, it was found that it is better to test washing effluent for BOD, COD and TSS since most of the waste plastic is collected from dump sites. 
Plastic waste collectors and recyclers are aware of environmental problems caused due to discharge of washing effluent into the environment without any treatment. Therefore majority (88\%) of polythene and plastic waste collectors and recyclers are willing to install a wastewater treatment plant for their industries. However, some are still reluctant to have a wastewater treatment plant due to the high costs associated with installation and maintenance.

Most of the recyclers complained that their companies are running under capacity due to insufficient collection of plastic materials. The quantities of plastic and polythene waste supplied for recycling industries are not adequate at present. This may be due to low participation of the public for plastic recycling activities by providing their polythene and plastic waste to the collection centers or collectors. Households are the biggest source of polythene and plastic waste, but recycling household plastics presents a number of challenges. One of these relates to collection. When polythene and plastic wastes are mixed with garbage, it is difficult to recover them from garbage waste stream. Therefore it is necessary to develop a system to collect household polythene and plastic waste before they reach the municipal waste stream.

As plastic identification and sorting is carried out by laborers with their experience, sometimes they may fail to recognize the exact type of plastic at once. In addition, it may be time consuming. Therefore new and practical sorting techniques have to be introduced at low cost to the polythene and plastic waste recycling industry in order to increase the efficiency of the plastic recycling process.

Plastic and polythene waste recycling industries are currently operating at small scale in Sri Lanka. This may be the reason for not having wastewater treatment plants in those industries. In addition, installation and maintenance cost of a wastewater treatment plant is high and it will reduce the industry's profit. As those industries are not having wastewater treatment plants, they are unable to reach the CEA standards for effluent quality before discharging to inland water bodies. Therefore they have a problem in obtaining EPL for their industries due to discharge of untreated wastewater to inland water bodies.

\section{CONCLUSION}

Recently with the solid waste crisis been highlighted, plastic and polythene are collected for recycling and cottage level recycling centers are in operation for these items in Sri Lanka. These businesses though happening at small scale are slowly increasing. About ninety five plastic and polythene recycling and collecting centers have been registered in the Central Environmental Authority. However, the scale is not adequate to make a significant impact because these industries are currently facing lot of issues and constraints regarding plastic waste collection, sorting, washing and marketing of manufactured products. In addition, the recycling process itself causes severe environmental pollution by discharging untreated washing effluent in to the inland water bodies. Therefore, it is necessary to find solutions to these issues by the government or other responsible organizations considering the environmental benefits of plastic waste recycling to reduce the amount of plastic waste accumulated in the environment.

However, the government has started promoting plastic waste recycling industry in Sri Lanka by providing financial assistance for the local authorities. Furthermore garbage bags and other necessary awareness programmes are provided for the public in order to collect plastic and polythene waste separately at houses. In addition, plastic waste recycling industry is becoming a profitable industry too. Therefore the people who are willing to invest on plastic recycling industries will be increased in the future. When the plastic recycling industry is developed, the issues related to the industry will also be high. For example: untreated washing effluents discharged to the inland water bodies may also be

Proceedings of the $15^{\text {th }}$ International Forestry and Environment Symposium, 26-27 November 2010.

Published by Department of Forestry and Environmental Science, University of Sri Jayewardenepura, Sri Lanka. 
high. Therefore it is necessary to find solutions for the issues related to plastic recycling industry before they become more severe in the future.

Financial assistance from the Central Environmental Authority is greatly acknowledged. 